\title{
EFFECTS OF HIGH AMBIENT TEMPERATURE ON FISH SPERM PLASMA MEMBRANE INTEGRITY AND MITOCHONDRIAL ACTIVITY - A FLOW CYTOMETRIC STUDY
}

\author{
SZabolcs TAmÁs Nagy, ${ }^{*}$ Balázs KaKasi, ${ }^{2}$ LÁSZló PÁL, ${ }^{1}$ \\ Máté Havasi, ${ }^{1,3}$ Miklós Bercsényi, ${ }^{1}$ Ferenc Husvéth ${ }^{1}$ \\ ${ }^{1}$ Department of Animal Sciences and Animal Husbandry, University of Pannonia, Georgikon Faculty, \\ Deák F. u. 16, H-8360 Keszthely, Hungary \\ 2Institute of Environmental Sciences, University of Pannonia, Wartha Vince u. 1, \\ H-8200 Veszprém, Hungary \\ ${ }^{3}$ Research Institute for Fisheries and Aquaculture, National Agricultural Research and \\ Innovation Centre
}

(Received: April 29, 2015; accepted: November 4, 2015)

\begin{abstract}
Local extreme climatic conditions occurring as a result of global climate change may interfere with the reproduction of animals. In the present study fish spermatozoa were incubated at different temperatures $\left(20,25,30\right.$ and $\left.40{ }^{\circ} \mathrm{C}\right)$ for 10 and 30 minutes, respectively and plasma membrane integrity and mitochondrial membrane potential changes were evaluated with flow cytometry using SYBR-14/PI and Mitotracker Deep Red FM fluorescent dyes. No significant differences were found in plasma membrane integrity at either incubation temperatures or time points. Mitotracker Deep Red FM histogram profiles indicating mitochondrial activity showed significant $(\mathrm{p}<0.001)$ alterations in all cases of higher $\left(25,30\right.$ and $\left.40{ }^{\circ} \mathrm{C}\right)$ temperature treatments as compared to the samples incubated at $20^{\circ} \mathrm{C}$. Our results indicate that fish spermatozoa exposed to high temperatures suffer sublethal damage that cannot be detected with conventional, vital staining techniques.
\end{abstract}

Keywords: Fish sperm - plasma membrane integrity - mitochondrial activity - high temperature - flow cytometry

\section{INTRODUCTION}

Local extreme climatic conditions occurring as a result of global climate change may disturb the physiological functions of wild and farm animals, involving their reproductive physiological processes [3]. It is known for example that extremely high or low temperatures result in disturbances in spermatogenesis causing several sperm defects [2].

Heat stress - besides changes at cellular level - can overthrow the sex-hormone balance of the organism and significantly affect the physiological process of animal production as well [22].

A number of animal species living at different temperate zones show strict seasonal reproduction where the main factor that triggers the onset of reproductive sea-

*Corresponding author; e-mail address: nagy.szabolcs@georgikon.hu 
son is the length of the daily light period instead of temperature. This latter does not fully follow the change of the day length which is a year-to-year precisely occurring phenomenon. This way there is a chance that the animals do not meet optimal temperature conditions in their reproductive period $[4,5]$.

The renaissance of ecological farming opens new fields for the old, traditional breeds, selected for extensive production methods. These breeds show more or less seasonality in reproduction, though this seasonality is not negligible in intensive type breeds either.

A majority of teleost fish species are seasonal breeders and may especially be sensitive to extreme environmental conditions, due to their external fertilization. Their reproductive success - and as a consequence, their fitness to reach brooder age - can be influenced by the extreme temperature affecting the gametes (eggs and sperm) either in the nature or during artificial propagation, gamete collection and storage $[18,24]$.

Our aim in this study was to assess the usefulness of flow cytometry to detect the changes of plasma membrane integrity and mitochondrial transmembrane potential of fish spermatozoa, incubated at different temperatures $\left(20,25,30\right.$ and $\left.40^{\circ} \mathrm{C}\right)$ for 10 and 30 minutes, respectively, to reveal if this increase of ambient temperature can lead to cell death or mitochondrial membrane depolarization.

\section{MATERIALS AND METHODS}

In order to decrease individual variance [21] pooled sperm of three male prussian carps (Carassius auratus gibelio, Bloch) were used in the experiment. Spermiation was induced by injecting carp pituitary extract into the body cavity and stripping was performed in anaesthesia using clove oil. Sperm samples were transferred to the laboratory immediately after collection and pooling. Sperm concentration was adjusted via suspending in phosphate buffered saline (PBS, Sigma-Aldrich P4417-100TAB) to achieve the optimal cell concentration $\left(<5 \times 10^{6} / \mathrm{ml}\right)$ for flow cytometric measurements. In order to avoid artefacts due to accidental activation of spermatozoa, activated/inactive state was monitored with an Olympus CX40 phase contrast microscope, and only inactive sperm samples were used for the subsequent analyses. Pooled sperm samples were split to eight subsamples, and they were incubated at $20,25,30$ or $40{ }^{\circ} \mathrm{C}$ for 10 or $30 \mathrm{~min}$, respectively. The experiment was repeated three times.

\section{Plasma membrane integrity}

The percentages of spermatozoa with intact plasma membrane were assessed with Live/Dead Sperm Viability Kit (Life Technologies, L-7011) according to Garner et al. [8]. Intact sperm cells were labelled with SYBR 14 and showed green fluorescence, dead cells were labelled with propidium iodide (PI) and showed red fluorescence. Events showing green and red fluorescent signal simultaneously were considered as moribund, dying spermatozoa (Fig. 1). 


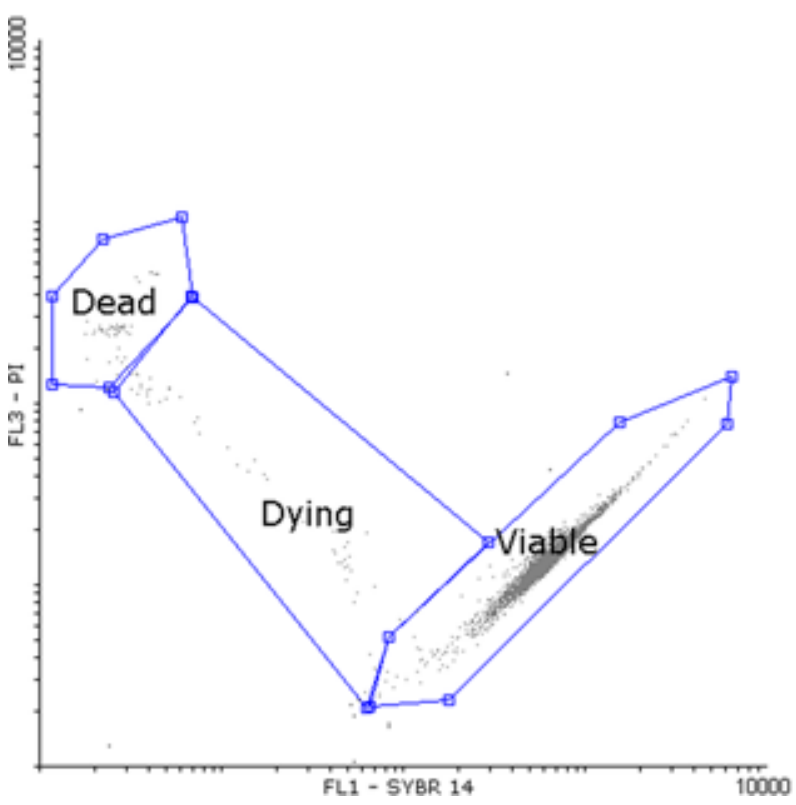

Fig. 1. Fluorescence intensities of viable, moribund and dead spermatozoa. Viable cells show high green, dead show high red signal, moribund, dying spermatozoa show high green and red fluorescence simultaneously. FL1: SYBR-14; FL3: PI

\section{Mitochondrial activity}

Mitochondrial transmembrane potential was evaluated with Mitotracker Deep Red FM (Life Technologies, M22426) fluorochrome according to Hallap et al. [12]. The fluorescent probe indicates high mitochondrial membrane potential with a high far red signal (Fig. 2).

\section{Flow cytometry}

Flow cytometric measurements were performed on a Beckman Coulter FC-500 flow cytometer equipped with a $488 \mathrm{~nm}$ Ar ion $(20 \mathrm{~mW})$ and a $635 \mathrm{~nm}$ red diode $(25 \mathrm{~mW})$ laser line. Fluorescent signals of SYBR 14, PI and Mitotracker Deep Red FM were evaluated on detectors FL 1 (525 BP), FL3 (620 SP) and FL 4 (675 BP), respectively. Forward and side scatter and fluorescent signals of 10,000 sperm events were recorded per sample using Beckman Coulter CXP acquisition software and stored as LMD files for subsequent analyses. 

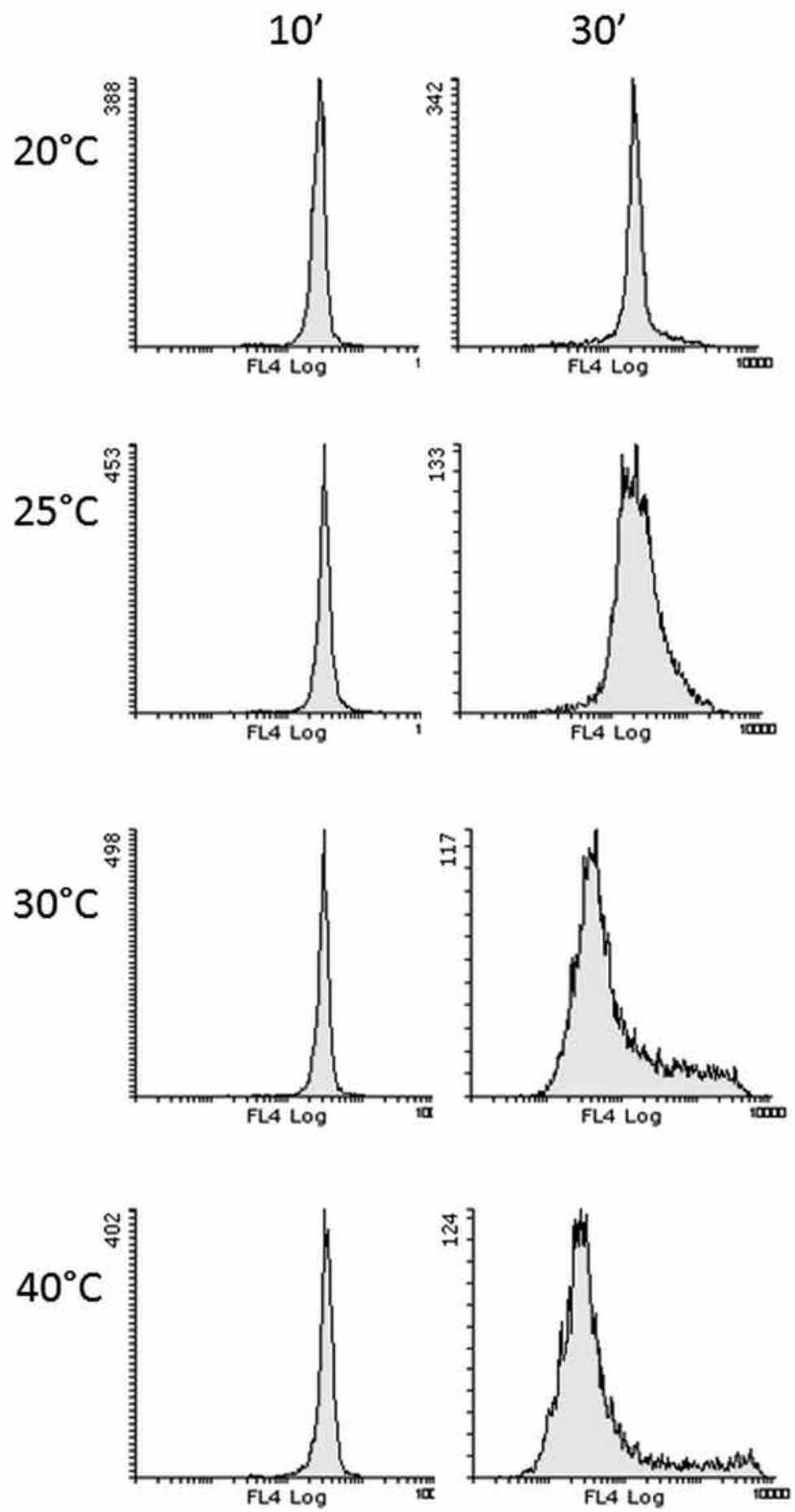

Fig. 2. Mitotracker Deep Red FM fluorescence intensity histograms of spermatozoa incubated at different temperatures for 10 or 30 minutes 


\section{Data analysis}

The LMD files were analyzed with the free Flowing 2.5.1. software (www.flowing. com). The main outcome of the plasma membrane integrity analysis was the percentage of SYBR-14 positive events (interpreted as \% viable). For the evaluation of mitochondrial membrane potential median fluorescence intensities (MFI - dimensionless value) of the Mitotracker Deep Red FM histograms were calculated. As spermatozoa contain more than one mitochondrion per cell and even within one cell there may be differences between individual mitochondria, in our opinion MFI may actually be a more sensitive indicator of the changes in mitochondrial membrane potential than the percentage of cells with high or low Mitotracker Deep Red FM fluorescence.

Viable \% values were analysed with Repeated Measures ANOVA and post-hoc Newman-Keuls tests using Statistica for Windows 8.0 (StatSoft, Inc., 2007. STATISTICA data analysis software system, www.statsoft.com). Mitotracker Deep Red FM histogram profiles were compared with the Kolmogorov-Smirnov option of the Beckman Coulter CXP analysis software, applying sample incubated for $10 \mathrm{~min}$ at room temperature $\left(20^{\circ} \mathrm{C}\right)$ as control. Cumulative histograms were overlaid to establish the maximum absolute differences $\left(D_{\max }\right)$, and to reveal whether the differences between histograms are significant or not at $p<0.05[6,24]$.

\section{RESULTS}

Our results did not reveal significant differences between different incubation temperatures and exposure intervals in plasma membrane integrity. The ratio of cells with intact plasma membrane remained about $99 \%$ in all cases (Table 1).

Determining mitochondrial activity measurements, the MFI values of the Mitotracker Deep Red FM histograms increased in case of $40{ }^{\circ} \mathrm{C}$ treatment after 10 minutes exposition, while the other treatments did not influence MFI significantly. These values were $285,287,275$ and 364 at $20,25,30$ and $40{ }^{\circ} \mathrm{C}$ incubation temperatures, respectively.

Table 1

Percentages of viable spermatozoa incubated at different temperatures for 10 and 30 minutes

\begin{tabular}{|c|c|c|c|c|}
\hline \multirow{2}{*}{$\begin{array}{c}\text { Temperature } \\
\left({ }^{\circ} \mathrm{C}\right)\end{array}$} & \multicolumn{2}{|c|}{$10 \mathrm{~min}$} & \multicolumn{2}{c|}{$30 \mathrm{~min}$} \\
\cline { 2 - 5 } & mean & $\mathrm{SD}$ & mean & $\mathrm{SD}$ \\
\hline 20 & 99.67 & 0.23 & 99.77 & 0.12 \\
\hline 25 & 99.46 & 0.42 & 99.70 & 0.20 \\
\hline 30 & 99.70 & 0.10 & 99.83 & 0.06 \\
\hline 40 & 99.67 & 0.21 & 99.73 & 0.21 \\
\hline
\end{tabular}

Means and SD-s of three replicates. 
The samples incubated at 30 or $40{ }^{\circ} \mathrm{C}$ showed significant fluorescence intensity decrease after 30 minutes exposition (MFI: 262, 296, 151 and 160 at 20, 25, 30 and $40{ }^{\circ} \mathrm{C}$ incubation temperatures, respectively).

The Kolmogorov-Smirnov test revealed significant $(p<0.001)$ differences in the Mitotracker Deep Red FM histogram profiles in all temperature treatments at both time intervals compared to the histogram of the sperm sample exposed to $20{ }^{\circ} \mathrm{C}$ for 10 minutes, regarded as control.

The $\mathrm{D}_{\max }$-values of the histogram comparisons are summarized in Table 2.

Table 2

Critical Kolmogorov-Smirnov $\mathrm{D}_{\max }$ values of the Mitotracker Deep Red FM histograms of the control measurement (incubation at $20{ }^{\circ} \mathrm{C}$ for $10 \mathrm{~min}$ ) and spermatozoa incubated at different temperatures and times

\begin{tabular}{|l|c|c|c|c|c|c|c|}
\hline \multicolumn{1}{|c|}{$\mathrm{D}_{\max }$} & A-B & A-C & A-D & A-E & A-F & A-G & A-H \\
\hline Mean & 0.31 & 0.32 & 0.57 & 0.56 & 0.58 & 0.60 & 0.67 \\
\hline SD & 0.26 & 0.09 & 0.31 & 0.25 & 0.30 & 0.29 & 0.23 \\
\hline
\end{tabular}

Means and SD-s of three replicates. A: $10^{\prime}, 20^{\circ} \mathrm{C}$; B: $30^{\prime}, 20^{\circ} \mathrm{C}$; C: $10^{\prime}, 25^{\circ} \mathrm{C}$; D: 30 ', $25^{\circ} \mathrm{C} ; \mathrm{E}: 10^{\prime}, 30^{\circ} \mathrm{C}$; F: $30^{\prime}, 30^{\circ} \mathrm{C}$; G: $10^{\prime}, 40^{\circ} \mathrm{C} ; \mathrm{H}: 30$ ', $40^{\circ} \mathrm{C}$.

\section{DISCUSSION}

Nearly $100 \%$ plasma membrane integrity of the freshly collected fish semen was showed earlier [19] and the high live-cell ratio was also observed in another species like carp [13]; striped bass [9, 10]; and zebrafish [11]. The plasma membrane lesion is a late end point of necrotic cell death. In this experiment, the intact cell ratio did not decrease in the semen samples, not even in the case of cells incubated at $40{ }^{\circ} \mathrm{C}$ for 30 minutes.

The mitochondrial membrane potential changes let us conclude that under the present experimental incubation time and temperature settings, the cells suffered sublethal damage which cannot be detected with conventional vital staining techniques. This phenomenon could be clearly observed in the case of spermatozoa with $40{ }^{\circ} \mathrm{C}$ incubation, where the mitochondria of the cells became hyperpolarized after 10 minutes, then after 30 minutes the decrease of MFI indicated the depolarization of mitochondrial membrane as compared to the sperm cells incubated at room temperature. Similar tendency was observed in sperm cells incubated at $30^{\circ} \mathrm{C}$, but less definitely. These results were considered biologically relevant as the results of Kolmogorov-Smirnov test demonstrated that the Mitotracker Deep Red FM histogram profiles significantly differed at all experimental times and temperatures from the histogram profile of the control sample $\left(10\right.$ minutes at $\left.20^{\circ} \mathrm{C}\right)$. The damage of sperm mitochondria might be initiators of a series of intracellular, degenerative processes. The main role of mitochondria of inactive fish sperm cells is to maintain the intracellular ATP levels, besides other homeostatic roles. Following the sperm activa- 
tion the spermatozoa use the stored ATP, instead of de novo synthesis of ATP generated by mitochondria. The increase of oxidative phosphorylation was not experienced together with the activation [16].

Similar phenomena can be observed at some mammalian species, the spermatozoa, of which contain only a few mitochondria (e.g. human - approx. 10-15 mitochondria per cell), the ATP synthesis needed for motility is mainly generated by glycolysis, the mitochondrial ATP synthesis is mainly required for sustaining plasma membranehomeostasis [7].

The spermatozoa of prussian carp contains only 10 mitochondria per cell [17], their role might be considered similarly as limited in active motility as in human spermatozoa. The damaged mitochondria are the main sources of intracellular oxidative lesions - the reactive oxygen species (ROS) released from the damaged, fragmented mitochondria may cause lipid-peroxidation and oxidative DNA lesions and finally DNA-fragmentation [1]. Moreover, mitochondria have an important role in the maintenance of $\mathrm{Ca}^{2+}$-homeostasis - the mitochondrial membrane depolarization causes decreased $\mathrm{Ca}^{2+}$ influx [20]. This latter and the increase in intracellular $\mathrm{Ca}^{2+}$ level are key components of fish sperm activation [15] and necessary for capacitation in mammalian spermatozoa [14].

According to our opinion, the present findings may provide useful information from the point of view of environment protection and conservation, may provide a basis for future experiments on fish sperm physiology, incorporating further assays such as the detection of intracellular $\mathrm{Ca}^{2+}$ level changes, oxidative DNA lesions and DNA fragmentations in fish spermatozoa exposed to extreme temperatures, and can be useful even for the practical specialists of aquaculture.

\section{ACKNOWLEDGEMENTS}

This study was supported by the project TÁMOP-4.2.2.A-11/1/KONV-2012-0064. The project was supported by the European Union, with co-funding from the European Social Fund.

\section{REFERENCES}

1. Aitken, R. J., De Iuliis G. N., Finnie J. M., Hedges A., McLachlan R. I. (2010) Analysis of the relationships between oxidative stress, DNA damage and sperm vitality in a patient population: development of diagnostic criteria. Hum. Reprod. 25, 2415-2426.

2. Barth, A. D., Oko, R. (1989) Abnormal morphology of bovine spermatozoa. Iowa State University Press, Ames.

3. Bradshaw, W. E., Holzapfel, C. M. (2006) Evolutionary response to rapid climate change. Science $312,1477-1478$.

4. Bronson, F. (2009) Climate change and seasonal reproduction in mammals. Philos. T. Roy. Soc. B. 364, 3331-3340.

5. Bronson, F. H. (1989) Mammalian reproductive biology. University of Chicago Press, Chicago.

6. Cox, C., Reeder, J. E., Robinson, R. D., Suppes, S. B., Wheeless, L. L. (1988) Comparison of frequency distributions in flow cytometry. Cytometry 9, 291-298. 
7. Cummins, J. (2009) 5-Sperm motility and energetics. In: Pitnick, T. R. B. J. H. (ed.) Sperm Biology Academic Press, London, pp. 185-206.

8. Garner, D., Johnson, L., Yue, S., Roth, B., Haugland, R. (1994) Dual DNA staining assessment of bovine sperm viability using SYBR-14 and propidium iodide. J. Androl. 15, 620-629.

9. Guthrie, H., Welch, G., Theisen, D., Woods, L. (2011) Effects of hypothermic storage on intracellular calcium, reactive oxygen species formation, mitochondrial function, motility, and plasma membrane integrity in striped bass (Morone saxatilis) sperm. Theriogenology 75, 951-961.

10. Guthrie, H., Woods, L., Long, J., Welch, G. (2008) Effects of osmolality on inner mitochondrial transmembrane potential and ATP content in spermatozoa recovered from the testes of striped bass (Morone saxatilis). Theriogenology 69, 1007-1012.

11. Hagedorn, M., Ricker, J., McCarthy, M., Meyers, S., Tiersch, T., Varga, Z., Kleinhans, F. (2009) Biophysics of zebrafish (Danio rerio) sperm. Cryobiology 58, 12-19.

12. Hallap, T., Nagy, S., Jaakma, Ü., Johannisson, A., Rodriguez-Martinez, H. (2005) Mitochondrial activity of frozen-thawed spermatozoa assessed by MitoTracker Deep Red 633. Theriogenology 63, 2311-2322.

13. Horváth, Á., Martínez-Páramo, S., Kovács, Á. I., Urbányi, B., Herráez, P. (2010) Effect of ovarian fluid on the mobility of fresh and cryopreserved sperm of the common carp (Cyprinus carpio L.). Állattani Közl. 95, 25-33. (In Hungarian)

14. Hossain, M. S., Johannisson, A., Wallgren, M., Nagy, S., Siqueira, A. P., Rodriguez-Martinez, H. (2011) Flow cytometry for the assessment of animal sperm integrity and functionality: state of the art. Asian J. Androl. 13, 406.

15. Inaba, K. (2008) Molecular mechanisms of the activation of flagellar motility in sperm. In: Alavi, S. M. H., Cosson, J. J., Coward, K., Rafiee, G. (ed.) Fish spermatology. Alpha Science International Ltd,, Oxford, UK, pp. 267-280.

16. Ingermann, R. L. (2008) Energy metabolism and respiration in fish spermatozoa. In: Alavi, S. M. H., Cosson, J. J., Coward, K., Rafiee, G. (ed.) Fish spermatology. Alpha Science International Ltd., Oxford, UK, pp. 215-240.

17. Jamieson, B. G. M. (1991) Fish Evolution and Systematics: Evidence from Spermatozoa: with a Survey of Lophophorate, Echinoderm, and Protochordate Sperm and an Account of Gamete Cryopreservation. Cambridge University Press, Cambridge.

18. Jonsson, B., Jonsson N. (2009) A review of the likely effects of climate change on anadromous Atlantic salmon Salmo salar and brown trout Salmo trutta, with particular reference to water temperature and flow. J. Fish Biol. 75, 2381-2447.

19. Nagy, S., Kakasi, B., Havasi, M., Németh, S., Pál, L., Bercsényi, M., Husvéth, F. (2013) Dynamic cellular changes during fish sperm activation as measured by flow cytometry. Diversification in Inland Finfish Aquaculture II, Vodnany, Czech Republic.

20. Pizzo, P., Drago, I., Filadi, R., Pozzan, T. (2012) Mitochondrial $\mathrm{Ca}^{2+}$ homeostasis: mechanism, role, and tissue specificities. Pflug. Arch. Eur. J. Phy. 464, 3-17.

21. Sood, S., Malecki, I., Tawang, A., Martin, G. (2012) Survival of emu (Dromaius novaehollandiae) sperm preserved at subzero temperatures and different cryoprotectant concentrations. Theriogenology $78,1557-1569$.

22. West, J. (2003) Effects of heat-stress on production in dairy cattle. J. Dairy Sci. 86, 2131-2144.

23. Young, I. T. (1977) Proof without prejudice: use of the Kolmogorov-Smirnov test for the analysis of histograms from flow systems and other sources. J. Histochem. Cytochem. 25, 935-941.

24. Zieba, G., Fox, M. G., Copp, G. H. (2010) The effect of elevated temperature on spawning of introduced pumpkinseed Lepomis gibbosus in Europe. J. Fish Biol. 77, 1850-1855. 